\title{
Evaluation of Personal and Built Environment Attributes to Physical Activity: A Multilevel Analysis on Multiple Population-Based Data Sources
}

\author{
Wei Yang, ${ }^{1}$ Karen Spears, ${ }^{2}$ Fan Zhang, ${ }^{2}$ Wai Lee, ${ }^{1}$ and Heidi L. Himler ${ }^{2}$ \\ ${ }^{1}$ School of Community Health Sciences, University of Nevada, Reno, 1664 North, Virginia Street, MS 274, Reno, NV 89557, USA \\ ${ }^{2}$ Department of Nutrition, University of Nevada, Reno, 1664 NV, Virginia Street, Reno, NV 89557, USA \\ Correspondence should be addressed to Wei Yang, weiyang@unr.edu
}

Received 27 October 2011; Revised 23 February 2012; Accepted 4 March 2012

Academic Editor: Norbert Schmitz

Copyright ( 2012 Wei Yang et al. This is an open access article distributed under the Creative Commons Attribution License, which permits unrestricted use, distribution, and reproduction in any medium, provided the original work is properly cited.

Background. Studies have documented that built environment factors potentially promote or impede leisure time physical activity (LTPA). This study explored the relationship between multiple built environment factors and individual characteristics on LTPA. Methods. Multiple data sources were utilized including individual level data for health behaviors and health status from the Nevada Behavioral Risk Factor Surveillance System (BRFSS) and community level data from different data sources including indicators for recreation facilities, safety, air quality, commute time, urbanization, population density, and land mix level. Mixed model logistic regression and geographic information system (GIS) spatial analysis were conducted. Results. Among 6,311 respondents, $24.4 \%$ reported no LTPA engagement during the past 30 days. No engagement in LTPA was significantly associated with (1) individual factors: older age, less education, lower income, being obesity, and low life satisfaction and (2) community factors: more commute time, higher crime rate, urban residence, higher population density, but not for density and distance to recreation facilities, air quality, and land mix. Conclusions. Multiple data systems including complex population survey and spatial analysis are valuable tools on health and built environment studies.

\section{Background}

It is stated that $24.1 \%$ of adult Americans were reported to be conducting no leisure time physical activities (LTPA) during the past month [1], and the US national prevalence of adult overweight and obesity (body mass index $>25 \mathrm{~kg} / \mathrm{m}^{2}$ ) is at $68.0 \%$ (95\% CI, 66.3\%-69.8\%) [2]. Research indicates that even a small increase in daily physical activity may prevent weight gain [3] and could limit the health complications associated with obesity, such as high blood pressure, type 2 diabetes, high cholesterol levels, and asthma [4].

Many factors have been attributed to inhibiting or promoting LTPA: environment, the built environment, public policy, and an individual's health status. Studies have documented that built environmental factors impede physical activity (PA) including limited connectivity of street layout, unsafe living areas (i.e., high violent crime rates, high property crime rates) $[5,6]$, air pollution $[7-9]$, poor urban design and land use mix [10-12], a high commuting time by car [13], and the lack of recreation facilities (i.e., parks, gyms, community centers, and swimming pools) $[9,14-16]$. Studies indicate that health factors that negatively influence physical activity comprise obesity, hypertension, cardiovascular disease, diabetes, chronic obstructive pulmonary disease (COPD), asthma, and health-related quality of life $[17,18]$. However, studies on LTPA involving individual level behaviors, health status, and other community level built environment factors based on statewide population-based complex sampling survey are lacking.

This study explores the relationship between LTPA and the built environment as well as other health indicators using both individual and community level data from multiple statewide population-based databases, which provides opportunities to reflect the real-world interactions between individual health behaviors and their built environment. 


\section{Methods}

2.1. Subjects. The study sample included adults who participated in the Nevada BRFSS telephone interviews from January 2006 through December 2007 ( $n=7,373)$. The BRFSS is a state-based telephone health survey that obtains information regarding an individual's health status, health risk behaviors, preventive health practices, and use/access to health care [19]. Standard US Center for Chronic Disease Prevention and Health Promotion (CDC) BRFSS sampling protocol was used.

Inclusion criteria for subject participation were as follows: (1) 18 years or older, (2) able to speak English, (3) phone was not a cellular phone number, (4) answered the physical activity question, (5) resided in a private residence within the State of Nevada, and (6) home was within a zip code with more than 30 BRFSS subjects. Oral consent was obtained prior to initiating the telephone interview. The Office of Human Subjects Research Protection, University of Nevada, Reno approved the study.

2.2. Study Variables. Data obtained from the 2006 and 2007 Nevada BRFSS included general individual demographics, chronic disease status, and life satisfaction. In addition, the subject's response to the binary dependent variable "During the past month, did you participate in any physical activities?" was also obtained. Each subject's residential geographic area was based upon their zip code and a "buffer zone" which refers to a geocoded spherical area in which the subject's home is the centroid.

Data regarding air quality, population density, commute time, distance to recreational facilities, property crime, and violent crime were obtained from multiple data sources based on zip codes. Datasets used were from the US Census Bureau, the US Environmental Protection Agency (EPA), the Environmental Systems Research Institute (ESRI), the Federal Highway Administration, and the Federal Bureau of Investigation or local law enforcement agencies.

The zip code-based independent variables were defined as follows.

(1) Air quality is based upon pollutant concentrations of ground-level ozone, particulate matter, carbon monoxide, sulfur dioxide, and nitrogen dioxide with good, fair, poor classifications set by the EPA.

(2) The 2000 US Census Bureau definitions of urbanization were used. Urban area refers to central city of $\geq 50,000$ persons and population density 1,000 persons per square mile. Urban cluster (sometimes referred to as suburban) has population of 2,500 to $<50,000$ persons inside a principal city or $>2,500$ persons outside urbanized areas and may contain adjoining territory with 500 to 1,000 persons per square mile. Rural area is all territory located outside urbanized areas and urban clusters (US Census Bureau, created April 30, 2002 and revised December 3, 2009).

(3) Population density is the midyear-estimated population of people divided by the land area (square mile).
(4) Commute time is the average minutes the residents in an area (zip-code) are required to conduct a one way commute to work by car.

(5) Property crime rates is the number of offenses of burglary, larceny theft, motor vehicle theft, and arson per 100,000 population.

(6) Violent crime was based upon four offenses: murder and no negligent manslaughter, forcible rape, robbery, and aggravated assault. The violent crime rate is reported per 100,000 population.

(7) Land mix level was calculated based on the ratio of numbers of stories divided by 100,000 population.

For those variables without specific classifications, they were divided to three groups based on $<33.3$ percentile, $33.3-$ 66.7 percentile, and $>66.6$ percentile, then renamed as low, medium, or high. For the variables only available for the county level, the zip codes within that county were categorized within the same category (low, medium, or high).

Individual-based independent variables were defined as follows.

(1) Overweight is a body mass index (BMI) between 25.0 and $29.9 \mathrm{~kg} / \mathrm{meter}^{2}$, and obese is a BMI $\geq$ $30 \mathrm{~kg} /$ meter $^{2}$.

(2) Demographic factors and health conditions such as age, sex, race, and diabetes.

(3) Distance to a recreational facility was presence of one or more recreational facilities within a 0.5 mile, 1 mile, or 3 miles radius from subjects' residence using ArcInfo version 9.2. The three groups are mutually exclusive, for example, if they answered yes to residing within 0.5 mile then they are excluded from the 1 or 3 mile groups. Recreational facilities include parks, golf courses, and fitness centers.

(4) Recreational facility density was the number of recreational facilities within a 0.5 mile, 1 mile (number $>0.5$ miles to 1 mile), or 3 miles (number $>1$ mile to 3 miles) radius from subjects' residence using ArcInfo version 9.2 .

2.3. Statistical Analysis. The analyses were weighted for the probability of survey sample selections: a telephone number, the number of adults in a household, and the number of telephones in a household. A final poststratification adjustment was made for nonresponses and households without telephones.

Since the data involves individual and community level variables, the multilevel mixed modeling logistic regression was conducted. The use of aggregate community level data, alone, to make inference about individual-level relationships can introduce bias due to heterogeneity in exposure variable of interest and other covariates within groups. Multilevel modeling takes into account the hierarchical structure of the data. The model used LTPA as the dependent variable and other risk factors including demographics, health status, and built environment factors (e.g., community crime rate, air 
TABLE 1: Characteristics of study participants $(n=6311)$.

\begin{tabular}{|c|c|c|c|}
\hline Factors & Categories & Study sample frequency & $\begin{array}{l}\text { Study sample } \\
\text { percentage }\end{array}$ \\
\hline \multirow{2}{*}{ Sex } & Male & 2761 & 43.8 \\
\hline & Female & 3550 & 56.3 \\
\hline \multirow{3}{*}{ Age } & Age 18 to 34 years & 1066 & 16.9 \\
\hline & Age 35 to 54 years & 2344 & 37.3 \\
\hline & Age 55 or older years & 2881 & 45.8 \\
\hline \multirow{3}{*}{ Education level } & $\begin{array}{l}\text { Didnot graduate or } \\
\text { graduated from high school }\end{array}$ & 2320 & 36.8 \\
\hline & $\begin{array}{l}\text { Attended college or } \\
\text { technical school }\end{array}$ & 2075 & 33.0 \\
\hline & $\begin{array}{l}\text { Graduated from college or } \\
\text { technical school }\end{array}$ & 1903 & 30.2 \\
\hline \multirow{2}{*}{ Marital status } & Single & 2702 & 42.9 \\
\hline & $\begin{array}{l}\text { Married or a member of an } \\
\text { unmarried couple }\end{array}$ & 3595 & 57.1 \\
\hline \multirow{4}{*}{ Race } & White/non-Hispanic & 4689 & 74.9 \\
\hline & Black/non-Hispanic & 145 & 2.3 \\
\hline & Hispanic & 677 & 10.8 \\
\hline & Other & 749 & 12.0 \\
\hline \multirow{3}{*}{ Annual household income } & Income less than $\$ 25,000$ & 1226 & 22.0 \\
\hline & $\begin{array}{l}\text { Income between } \$ 25,000 \\
\text { and } \$ 50,000\end{array}$ & 1572 & 28.2 \\
\hline & Income more than $\$ 50,000$ & 2785 & 49.9 \\
\hline \multirow{2}{*}{ Employment status } & Out of work & 2685 & 42.7 \\
\hline & Employed or self-employed & 3611 & 57.4 \\
\hline \multirow{2}{*}{$\begin{array}{l}\text { Engaged in leisure time physical } \\
\text { activity within the past } 30 \text { days }\end{array}$} & Yes & 4758 & $75.4 \%$ \\
\hline & No & 1553 & $24.4 \%$ \\
\hline
\end{tabular}

quality, population density, and commute time) as independent variables. After individually evaluating the relationships between LTPA, health status, and built environment factors, demographic data were added as control factors to obtain the final model. Demographic factors entered were age, gender, race/ethnicity, education, income, employment, and marital status. The "buffer zone" categories were then added to the model.

ArcInfo version 9.2 was used for the decoding and buffer zone analysis. Statistical software SAS version 9.1 was utilized for both descriptive and multilevel mixed model logistic regressions analyses.

\section{Results}

Among 6,311 study participants, 56.3\% were female, and $45.8 \%$ aged 55 years or older (Table 1). A total of $75.6 \%$ participants reported engaging in LTPA during the past 30 days. Compared to others, male (77.34\%), age 18-34 years old $(77.01 \%)$, White/non-Hispanic $(78.67 \%)$, higher income $(82.91 \%)$, and higher educated $(84.46 \%)$ groups have higher prevalence of engaging in LTPA (Table 2).

The adjusted odds ratios in Table 3 were derived from the multilevel mixed model logistic regressions as outlined in the statistical method section, which were adjusted for sex, age, race, marital status, annual household income, education level, and employment status. Among demographic factors, significantly associated with LTPA, are younger age (age 1834 versus age $>55$ AOR 1.84; age $35-54$ versus age $>55$ AOR 1.27), higher education (graduated college versus less than college AOR 1.80; graduated college versus some college AOR 1.36), and higher income (high income versus low income AOR 1.92; high income versus middle income AOR 1.52). sex, race, and marital and employment status did not significantly differ.

Self-reported overall good health, life satisfaction, and health insurance are significantly related to engaging in LTPA (AOR 2.37, 1.95, and 1.32, resp.). In addition, subjects who are neither overweight nor obese (AOR 1.57) or overweight (AOR 1.41) have significantly higher odds of engaging in LTPA than subjects who are obese. Respondents with or without diabetes or asthma showed no significant LTPA difference.

Among built environment community level indicators, factors significantly associated with LTPA included less commute time (AOR 1.28), lower violent crime (AOR 1.43), lower property crime (AOR 1.58), living in rural (versus urban) (AOR 1.29), and living in less population dense 
TABLE 2: Weighted prevalence of potential factors related to conducting physical activity.

\begin{tabular}{|c|c|c|c|c|c|c|}
\hline & Factors & Categories & Frequency & Weighted & $95 \% \mathrm{CI}^{*}$ fo & percentage \\
\hline & $\operatorname{Sex}(n=4796)$ & Male & 2151 & 77.34 & 74.95 & 79.73 \\
\hline & & Female & 2645 & 72.53 & 70.22 & 74.83 \\
\hline & & Age 18 to 34 years & 858 & 77.01 & 73.24 & 80.78 \\
\hline & Age $(n=4782)$ & Age 35 to 54 years & 1839 & 76.83 & 74.33 & 79.33 \\
\hline & & Age 55 or older years & 2085 & 70.9 & 68.53 & 73.27 \\
\hline & & White/non-Hispanic & 3657 & 78.67 & 76.95 & 80.39 \\
\hline & Race $(n=4752)$ & Black/non-Hispanic & 101 & 71.59 & 62.53 & 80.66 \\
\hline & & Hispanic & 455 & 65.45 & 60.32 & 70.59 \\
\hline & & Other & 539 & 70.4 & 65.26 & 75.54 \\
\hline & Marital status $(n=4784)$ & Single & 1932 & 71.8 & 68.93 & 74.68 \\
\hline & & $\begin{array}{l}\text { Married or a member of an } \\
\text { unmarried couple }\end{array}$ & 2852 & 76.77 & 74.74 & 78.8 \\
\hline & & Income less than 35,000 & 751 & 61.13 & 56.63 & 65.62 \\
\hline Individual level & $(n=4279)$ & $\begin{array}{l}\text { Income between } 35,000 \\
\text { and } 50,000\end{array}$ & 1162 & 72.87 & 69.49 & 76.25 \\
\hline & & Income more than 50,000 & 2366 & 82.91 & 80.8 & 85.01 \\
\hline & Education level & $\begin{array}{l}\text { Didnot graduate or } \\
\text { graduated from high school }\end{array}$ & 1562 & 66.21 & 63.17 & 69.25 \\
\hline & $(n=4787)$ & $\begin{array}{l}\text { Attended college or } \\
\text { technical school }\end{array}$ & 1596 & 77.37 & 74.63 & 80.11 \\
\hline & & $\begin{array}{l}\text { Graduated from college or } \\
\text { technical school }\end{array}$ & 1629 & 84.46 & 82.07 & 86.85 \\
\hline & Employment status & Out of work & 1898 & 69.64 & 66.95 & 72.33 \\
\hline & & Employed or self-employed & 2886 & 78.12 & 76 & 80.23 \\
\hline & General overall health & Fair or poor & 580 & 54.31 & 49.74 & 58.88 \\
\hline & & Excellent/very good/good & 4208 & 79.11 & 77.35 & 80.87 \\
\hline & Life satisfaction & Satisfied & 4465 & 76.13 & 74.41 & 77.86 \\
\hline & & Dissatisfied & 198 & 53.23 & 45.53 & 60.93 \\
\hline & $\begin{array}{l}\text { Diabetes status } \\
(n=4792)\end{array}$ & $\begin{array}{l}\text { No prediabetes or boarder } \\
\text { line diabetes }\end{array}$ & 4417 & 75.88 & 74.14 & 77.62 \\
\hline & & Yes & 375 & 63.79 & 58.35 & 69.22 \\
\hline & Body mass index & $\begin{array}{l}\text { Neither overweight nor } \\
\text { obese }\end{array}$ & 1800 & 78.58 & 75.94 & 81.23 \\
\hline & & Overweight & 1822 & 77.05 & 74.39 & 79.71 \\
\hline & & Obese & 1041 & 67.81 & 64.17 & 71.44 \\
\hline & & Current & 372 & 69.21 & 63.21 & 75.21 \\
\hline & Asthma status $(n=5112)$ & Former & 206 & 78 & 69.62 & 86.38 \\
\hline & & Never & 4159 & 75.24 & 73.46 & 77.03 \\
\hline
\end{tabular}


TABle 2: Continued.

\begin{tabular}{|c|c|c|c|c|c|c|}
\hline & Factors & Categories & Frequency & Weighted & $95 \% \mathrm{CI}^{*}$ fo & percentage \\
\hline & & Low crime & 1638 & 77.07 & 74.39 & 79.75 \\
\hline & $(n=4796)$ & Middle crime & 1960 & 79.77 & 77.78 & 81.76 \\
\hline & & High crime & 1198 & 72.48 & 69.89 & 75.07 \\
\hline & & Low crime & 725 & 79.15 & 75.76 & 82.54 \\
\hline & $(n=4796)$ & Middle crime & 2843 & 76.88 & 74.7 & 79.07 \\
\hline & & High crime & 1228 & 72.81 & 70.14 & 75.47 \\
\hline & & Good & 758 & 74.36 & 70.81 & 77.91 \\
\hline & Air quality $(n=4796)$ & Fair & 154 & 65.95 & 58.32 & 73.59 \\
\hline & & Poor & 3884 & 75.13 & 73.34 & 76.91 \\
\hline Community level & Somp $x$ & Less commute time & 1605 & 77.34 & 74.78 & 79.89 \\
\hline & $(n=4556)$ & Middle commute time & 1409 & 73.86 & 70.93 & 76.8 \\
\hline & & More commute time & 1542 & 74.68 & 71.98 & 77.39 \\
\hline & Dorulation Doncits & Low density & 1572 & 77.18 & 74.73 & 79.63 \\
\hline & (per Sq mile) $(n=4796)$ & Middle density & 1657 & 79.28 & 76.50 & 82.06 \\
\hline & & High density & 1567 & 71.91 & 69.36 & 74.45 \\
\hline & & Rural & 2779 & 79.09 & 77.06 & 81.11 \\
\hline & Urbanized $(n=4796)$ & Suburban & 735 & 73.84 & 70.09 & 77.58 \\
\hline & & Urban & 1282 & 72.18 & 69.27 & 75.08 \\
\hline & & Low land mix level & 1542 & 74.39 & 71.61 & 77.17 \\
\hline & Land mix level $(n=4796)$ & Middle land mix level & 1681 & 76.37 & 73.63 & 79.11 \\
\hline & & High land mix level & 1573 & 74.22 & 71.23 & 77.21 \\
\hline
\end{tabular}

Of the 7,373 eligible study participants, 6,311 answered the questions regarding demographics and physical activity and included in the analysis.

${ }^{*} \mathrm{CI}=$ confidence interval.

areas (AOR 1.31). Factors not significantly associated with LTPA were residential distance to a park, recreation facility (Table 4), air quality, or land mix.

\section{Discussion}

This statewide study indicated that all health indicators, except diabetes and asthma status, and the majority of built environment factors (commute time, community safety, population density, and rural residence) were significantly associated to LTPA after controlling for sex, age, race, marital status, annual household income, education level, and employment status. However, the likelihood of engaging in LTPA was not significant related to density and distance to a recreation facility, air quality, and land mix.

Therefore, potential factors that could encourage LTPA are reporting good health status or life satisfaction, not being obese, high community safety, and residing in less urbanized areas. These findings emphasize the need to include personal-level factors when examining the interaction between individuals and their environment. Furthermore, access to recreation facilities may not directly be a driving force for participation in LTPA. This study's results align with some, but not all, previous findings.

4.1. Health-Related Quality of Life. Those who reported overall good health and life satisfaction were twofold as likely to engage in LTPA compared to those who reported poor health and not being satisfied with their life (AOR 1.95; CI: $1.51,2.52$ ). This is consistent with the 2001 BRFSS national data. Brown et al. revealed men exhibited 0.54 (95\% CI 0.48, 0.62 ) and women 0.64 (95\% CI $0.58,0.71)$ odds of reporting impaired mental health between those conducting moderate or vigorous physical activity levels to inactive respondents after adjusting for age, race, education, smoking status, and BMI [20].

It remains debatable whether those in good health and satisfied with life are more vibrant and interested in 
TABLE 3: Adjusted odds ratio for factors related to conducting leisure time physical activity.

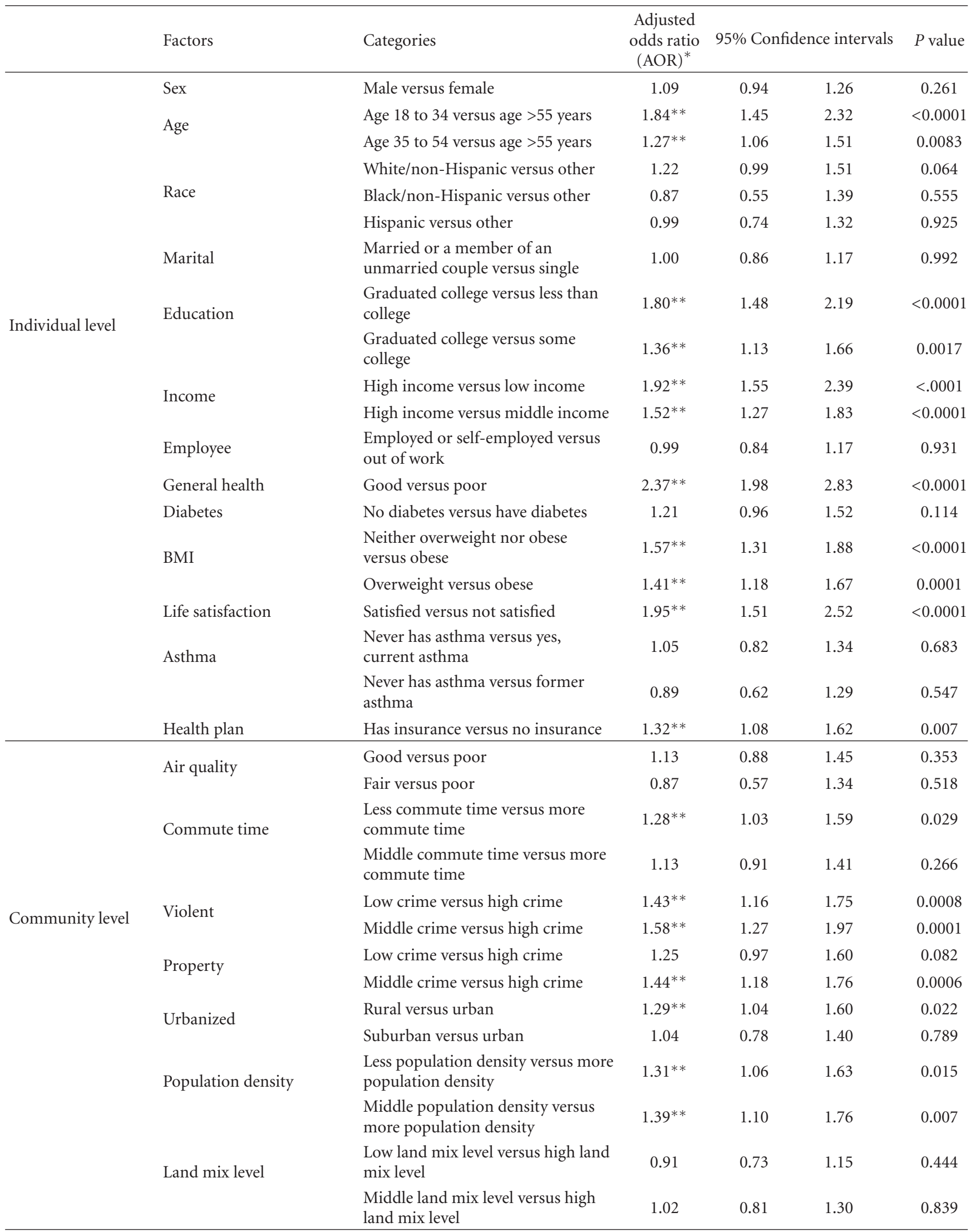

*Community level odds ratios were adjusted for sex, age, race, marital status, annual household income, education level, and employee status.

** Significant $<0.05 P$ value level. 
TABLE 4: Relationship between distance to recreation facilities and leisure physical activity.

\begin{tabular}{|c|c|c|c|c|}
\hline Categories & Adjusted odds ratio (AOR) ${ }^{*}$ & \multicolumn{2}{|c|}{ 95\% confidence intervals } & $P$ value \\
\hline Within 0.5 mile buffer zone distance** & 1.16 & 0.75 & 1.80 & 0.51 \\
\hline Within 1 mile buffer zone distance & 1.05 & 0.75 & 1.48 & 0.77 \\
\hline Within 3 mile buffer zone distance & 1.20 & 0.83 & 1.72 & 0.34 \\
\hline
\end{tabular}

* Odds ratios were adjusted for sex, age, race, marital status, annual household income, education level, and employee status.

** Buffer zone is ageocoded spherical area in which the subject's home is the centroid.

conducting physical activity than those in poor health or unsatisfied with life. Studies observed that PA reduced the prevalence of impaired mental health status, and others found that initiating a physical activity program significantly improved subjects' psychological well being [20].

4.2. Safety. Neighborhood safety is a salient concern, a frequently reported LTPA impediment by subjects $[5,6,21]$; however, findings are consistently using less objective crimerelated measures $[5,6]$. Studies, similar to this study, found individuals living in more crime-prone areas engaged in less LTPA than those living in low-crime neighborhoods $[6,22]$. Reviewing published studies, Foster and GilesCorti surmised, for the most part, respondents' emotional perception of safety, specifically "fear" of crime, elicits a strong constraint on PA behavior (generally walking), yet the built environment cannot be ignored [5].

4.3. Urbanization/Population Density/Land Mix. This study investigated three geographic constructs: urbanization, population density, and land mix regarding an individual's transport choice. The study findings disclosed that those residing in rural or low-populated density areas in Nevada were more likely to be more active than urban or higher population density area residents (AOR 1.29; CI 1.041 .60 and AOR 1.23; CI 1.07, 1.42, resp.), which contradict the bulk of the literature, including the National Health Interview Survey [10, 12, 23-25]. This questions the belief that rural residents' LTPA is inhibited by isolation, distance, cost of transportation, lack of PA facilities, and insufficient infrastructure [12, 26, 27]. Furthermore, the current findings oppose earlier studies where higher density neighborhoods have higher levels of LTPA [7, 12, 28, 29].

The CDC found a dose response; PA decreases by degree of rurality [27] not observed in this study. There was no significant difference between suburban and urban residents (Table 3). Many reasons have been set forth for the lack of the observed dose response. One aspect is the variance in geographic classification. Rural living includes overlapping elements of population density and land mix. As aforementioned, Nevada is composed of two major metropolitan areas with adjacent suburbs and vast expanses between small cities/townships; therefore, rural classification may capture characteristics of living in proximity to facilities and social support. In addition, population density delineated areas are unrelated to categorical township (population of people divided by the land area). Others have postulated that a threshold exists for population density. Increasing density levels will reduce vehicle motor transport, but only above a certain threshold level [10]. Furthermore, no single definition is used compounding the variance in observed results. Researchers acknowledge this weakness in measuring the relationship between built environment and PA $[28,30]$.

Land mix attempts to capture convenience, a balanced mix of destinations (i.e., stores, service, and work) in walkable or biking distance from their residence [31]. Studies found residents do not take advantage of opportunities of running errands on bicycle or foot [32]. The Federal Highway Administration national transportation data found that although the destinations are in walking or biking distance, more than $90 \%$ of all trips take place by automobile [7]. Air pollution and the weather modify an individual's travel choice and outdoor activity $[8,9,33]$. The frequency warnings to limit outdoor exposure during the fire session in Nevada may account for the lack of significant association between land mix and LTPA found in this study (AOR 0.911.02; $P$ value $>0.05$ ).

4.4. Density and Distance to Recreation Facilities. Over the years, the number of studies evaluating convenient recreation facilities and physical activity has grown exponentially. It is now recognized that access to recreational opportunities may not independently influence sedentary behavior [14, $34,35]$. More in-depth exploration uncovers the complexity components of the relationship $[28,35]$.

Several systematic literature reviews [5, 28, 35-37] found a "reasonably" positive relationship for access, availability, and convenience of recreational facilities to physical activity. Yet, ambiguity exists regarding the direction (positive, negative, null, or mixed correlates) [5, 14, 16, 28, 35-39]. Within multiple literature reviews, only half of the studies exhibited a significant positive association with higher PA intensity influencing density and distance study outcomes $[14,16,37]$. The current study provides further documentation that an individual's likelihood of conducing LTPA is not significantly interrelated to the density or distance to physical activity facilities at the $0.5,1.0$, and 3.0 miles buffer zones from their residents (Table 4 ).

A major limitation in this study arises from the design of the BRFSS survey. It is a cross-sectional, self-report survey and subject to recall and reporting bias. Sedentary adults tend to inaccurately report their physical activity intensity [40]. In addition, the BRFSS excludes persons residing in households without telephones and those households that rely solely on cell phones. However, in order to overcome these limitations, especially addressing nonresponse and 
exclusion biases, the data analysis process included weighting procedures to equalize the probabilities among the census population distributions.

Another BRFSS sampling bias may have been introduced because about $15 \%$ of BRFSS subjects had insufficient data for geographical coding. An accurate physical address was required to establish subjects' residence within a zip code and to create a "buffer zone." Without this pertinent information geographical coding was not possible.

Additionally, GIS and other databases used were purchased or obtained by various agencies and industries. Some of the data may not represent current information. Furthermore, merging these various databases required developing new constructs.

The generalizability of the findings from this study may be limited by the characteristics of Nevada geographic and demographics. As indicated previously, Nevada has two major cities and a vast expanse between rural towns and has distinct fire sessions that may limit outdoor activities based on air quality. However, the multiple data systems and GIS spatial analysis procedure may be an effective means for other states to determine associations between physical activity and built environment and individuals characteristics.

This study has several strengths. GIS data was obtained for the whole state providing uniquely diverse categories for built environment factors. Statewide BRFSS was used providing a rich database for a specific subject's demographic and health status which enables accessing risk factors of outdoor or nonoutdoor physical activity at both individual level and community level.

\section{Conclusion}

This study found that incorporating multiple data systems and GIS spatial analysis was a valuable tool in analyzing a complex population survey. In addition, physiological and psychological factors that affect overall health and life satisfaction should not be overlooked. Reporting good health and life satisfaction were the two most "powerful" correlates to engaging in LTPA with adjusted odds ratios 2.37 and 1.95, respectively. Future studies are needed to determine if good health and life satisfaction promote physical activity or if physical activity promotes good health and life satisfaction. The present results suggest policy makers should consider strategies, physiological and/or environmental, to enhance life satisfaction. As well as approaches to reduce violence, property crime rates, and commute time, focusing special attention on Nevada residents who are low-income, older, and living in urban or more population dense areas.

\section{Acknowledgments}

Funding was obtained from the Nevada Trust Fund for Public Health and Nevada Agricultural Experiment Station's Hatch Act grant. The funding sources had no involvement in any aspect of study design and implementation. No conflict of interests exist for all authors.

\section{References}

[1] Centers for Disease Control and Prevention (CDC), State Indicator Report on Physical Activity, 2010, US Department of Health and Human Services, Atlanta, Ga, USA, 2010.

[2] K. M. Flegal, M. D. Carroll, C. L. Ogden, and L. R. Curtin, "Prevalence and trends in obesity among US adults, 19992008," Journal of the American Medical Association, vol. 303, no. 3, pp. 235-241, 2010.

[3] A. Morabia and M. C. Costanza, "Does walking 15 minutes per day keep the obesity epidemic away? simulation of the efficacy of a population-wide Campaign," American Journal of Public Health, vol. 94, no. 3, pp. 437-440, 2004.

[4] U.S. Department of Health and Human Services, The Surgeon General's Call to Action to Prevent and Decrease Overweight and Obesity, U.S. Department of Health and Human Services, Publich Health Service, Office of the Surgeon General, Rockville, Md, USA, 2001.

[5] S. Foster and B. Giles-Corti, "The built environment, neighborhood crime and constrained physical activity: an exploration of inconsistent findings," Preventive Medicine, vol. 47, no. 3, pp. 241-251, 2008.

[6] C. G. Roman and A. Chalfin, "Fear of walking outdoors. A multilevel ecologic analysis of crime and disorder," American Journal of Preventive Medicine, vol. 34, no. 4, pp. 306-312, 2008.

[7] R. Ewing and R. Kreutzer, "Understanding the relationship between public health and the built environment," Report prepared for the Leasership in Energy and Environmental Design for Neighborhood Development (LEED-ND) Core Committee, May 2006.

[8] L. D. Frank and P. Engelke, "Multiple impacts of the built environment on public health: walkable places and the exposure to air pollution," International Regional Science Review, vol. 28, no. 2, pp. 193-216, 2005.

[9] N. Owen, N. Humpel, E. Leslie, A. Bauman, and J. F. Sallis, "Understanding environmental influences on walking: review and research agenda," American Journal of Preventive Medicine, vol. 27, no. 1, pp. 67-76, 2004.

[10] L. D. Frank and P. Engelke, How Land Use and Transportation Systems Impact Public Health: A Literature Review of the Relationship Between Physical Activity and Built form working paper \#1, Georgia Institute of Technology, 2010, http://www.cdc .gov/nccdphp/dnpa/pdf/aces-workingpaper1.pdf.

[11] P. J. Troped, R. P. Saunders, R. R. Pate, B. Reininger, J. R. Ureda, and S. J. Thompson, "Associations between self-reported and objective physical environmental factors and use of a community rail-trail," Preventive Medicine, vol. 32, no. 2, pp. 191-200, 2001.

[12] J. P. Reis, H. R. Bowles, B. E. Ainsworth, K. D. Dubose, S. Smith, and J. N. Laditka, "Nonoccupational physical activity by degree of urbanization and U.S. geographic region," Medicine and Science in Sports and Exercise, vol. 36, no. 12, pp. 2093-2098, 2004.

[13] L. D. Frank, B. E. Saelens, K. E. Powell, and J. E. Chapman, "Stepping towards causation: do built environments or neighborhood and travel preferences explain physical activity, driving, and obesity?" Social Science and Medicine, vol. 65, no. 9, pp. 1898-1914, 2007.

[14] N. Humpel, N. Owen, and E. Leslie, "Environmental factors associated with adults' participation in physical activity. a review," American Journal of Preventive Medicine, vol. 22, no. 3, pp. 188-199, 2002. 
[15] A. V. Diez-Roux, C. I. Kiefe, D. R. Jacobs Jr. et al., "Area characteristics and individual-level socioeconomic position indicators in three population-based epidemiologic studies," Annals of Epidemiology, vol. 11, no. 6, pp. 395-405, 2001.

[16] W. Wendel-Vos, M. Droomers, S. Kremers, J. Brug, and F. van Lenthe, "Potential environmental determinants of physical activity in adults: a systematic review," Obesity Reviews, vol. 8, no. 5, pp. 425-440, 2007.

[17] R. Bize, J. A. Johnson, and R. C. Plotnikoff, "Physical activity level and health-related quality of life in the general adult population: a systematic review," Preventive Medicine, vol. 45, no. 6, pp. 401-415, 2007.

[18] G. C. Wendel-Vos, A. J. Schuit, M. A. Tijhuis, and D. Kromhout, "Leisure time physical activity and health-related quality of life: cross-sectional and longitudinal associations," Quality of Life Research, vol. 13, no. 3, pp. 667-677, 2004.

[19] Centers for Disease Control and Prevention (CDC), Behavioral Risk Factor Surveillance System Survey Data, US Department of Health and Human Services, Centers for Disease Control and Prevention, Atlanta, Ga, USA, 2006/2007.

[20] D. W. Brown, L. S. Balluz, G. W. Heath et al., "Associations between recommended levels of physical activity and healthrelated quality of life: findings from the 2001 Behavioral Risk Factor Surveillance System (BRFSS) survey," Preventive Medicine, vol. 37, no. 5, pp. 520-528, 2003.

[21] A. Loukaitou-Sideris and J. E. Eck, "Crime prevention and active living," American Journal of Health Promotion, vol. 21, no. 4, pp. 380-389, 2007.

[22] S. Doyle, A. Kelly-Schwartz, M. Schlossberg, and J. Stockard, "Active community environments and health: the relationship of walkable and safe communities to individual health," Journal of the American Planning Association, vol. 72, no. 1, pp. 19-32, 2006.

[23] K. J. Bennett, B. Olatosi, and J. C. Probst, Health Disparities: A rural-Urban Chartbook, South Carolina Rural Health Research Center, Columbia, SC, USA, 2008, http://www.ruralhealthresearch.org/.

[24] Centers for Disease Control and Prevention (CDC), "Neighborhood safety and the prevalence of physical inactivityselected states, 1996," Morbidity and Mortality Weekly Report, vol. 48, no. 7, pp. 143-146, 1999.

[25] Centers for Disease Control and Prevention (CDC), "Vital and Health Statistics: Summary Health Statistics U.S. Adults: National Health Interview Survey, 2009," DHHS Publication No (PHS) 2011-1577, August 2010, series 10, no. 249.

[26] S. Wilcox, C. Castro, A. C. King, R. Housemann, and R. C. Brownson, "Determinants of leisure time physical activity in rural compared with urban older and ethnically diverse women in the United States," Journal of Epidemiology and Community Health, vol. 54, no. 9, pp. 667-672, 2000.

[27] Centers for Disease Control and Prevention (CDC), "Selfreported physical inactivity by degree of unbanizationUnited States 1996," in Morbidity and Mortality Weekly Report, vol. 47, U.S. Government Printing Office (GPO), Washington, DC, USA, Superintendent of Documents, 1998.

[28] R. C. Brownson, C. M. Hoehner, K. Day, A. Forsyth, and J. F. Sallis, "Measuring the built environment for physical activity. state of the science," American Journal of Preventive Medicine, vol. 36, no. 4, article e112, pp. S99-S123, 2009.

[29] R. Ewing, T. Schmid, R. Killingsworth, A. Zlot, and S. Raudenbush, "Relationship between urban sprawl and physical activity, obesity, and morbidity," American Journal of Health Promotion, vol. 18, no. 1, pp. 47-57, 2003.
[30] J. F. Sallis, "Measuring physical activity environments: a brief history," American Journal of Preventive Medicine, vol. 36, no. 4, pp. S86-S92, 2009.

[31] S. L. Handy, "Critial assessment of the literature on the relationships among transportations, land use, and physical activity," Transportation Research Record: Journal of the Transportation Research Board and Institute of Medicine Committe on Physical Activity, Health, Transporation, and Land Use, Special report, 2004.

[32] Y. Fan and A. J. Khattak, "Does urban form matter in solo and joint activity engagement?" Landscape and Urban Planning, vol. 92, no. 3-4, pp. 199-209, 2009.

[33] A. de Nazelle, D. A. Rodriguez, and D. Crawford-Brown, "The built environment and health: impacts of pedestrianfriendly designs on air pollution exposure," Science of the Total Environment, vol. 407, no. 8, pp. 2525-2535, 2009.

[34] B. Giles-Corti and R. J. Donovan, "The relative influence of individual, social and physical environment determinants of physical activity," Social Science and Medicine, vol. 54, no. 12, pp. 1793-1812, 2002.

[35] A. E. Bauman and F. C. Bull, Environmental correlates of physical activity and walking in adults and children: a review of reviews, National Institute of Health and Clinical Excellence School of Sports and Exercise Science Loughborough University, February 2007.

[36] A. Renalds, T. H. Smith, and P. J. Hale, "A systematic review of built environment and health," Family and Community Health, vol. 33, no. 1, pp. 68-78, 2010.

[37] A. T. Kaczynski and K. A. Henderson, "Environmental correlates of physical activity: a review of evidence about parks and recreation," Leisure Sciences, vol. 29, no. 4, pp. 315-354, 2007.

[38] Transportation Research Board, "Does the built environment influence physical activity? Examining the evidence," Special Report 282, Transport Reserach Board Business Office, Washington, DC, USA, Edited by Sciences NAo, 2005.

[39] A. T. Kaczynskl and K. A. Henderson, "Parks and recreation settings and active living: a review of associations with physical activity function and intensity," Journal of Physical Activity and Health, vol. 5, no. 4, pp. 619-632, 2008.

[40] G. E. Duncan, S. J. Sydeman, M. G. Perri, M. C. Limacher, and A. D. Martin, "Can sedentary adults accurately recall the intensity of their physical activity?" Preventive Medicine, vol. 33, no. 1, pp. 18-26, 2001. 


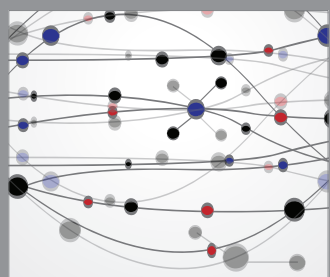

The Scientific World Journal
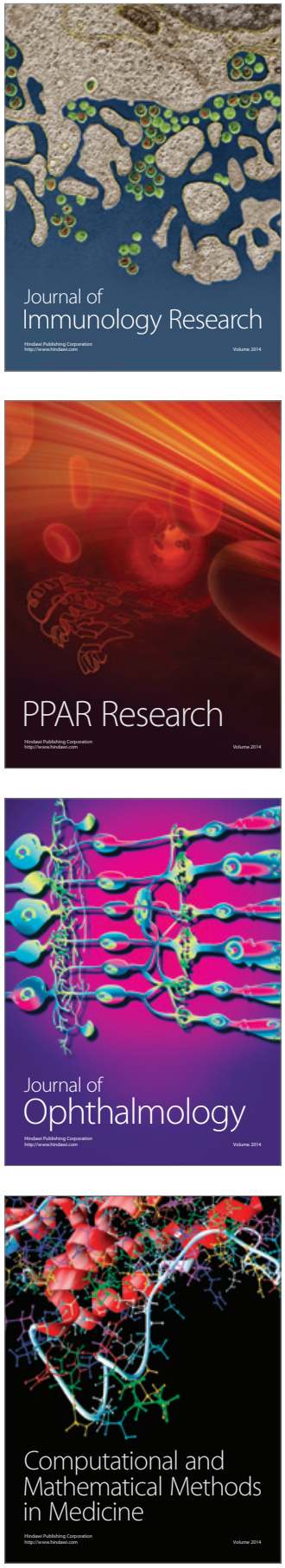

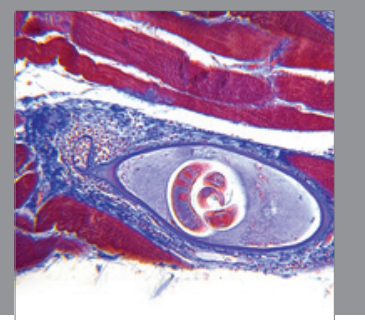

Gastroenterology

Research and Practice
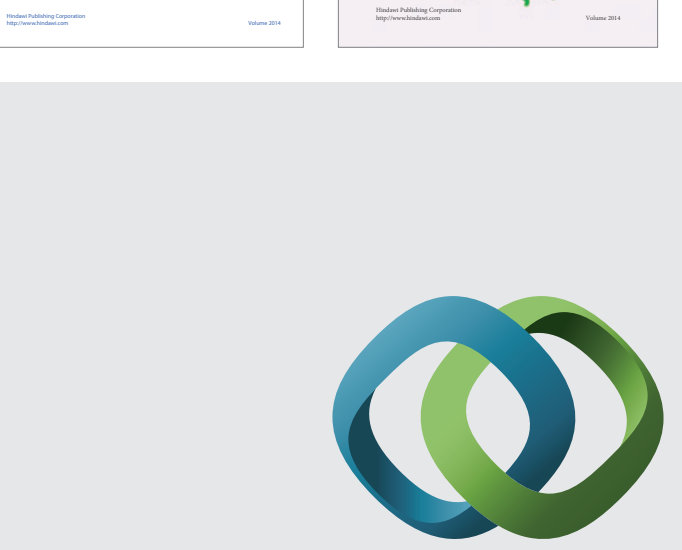

\section{Hindawi}

Submit your manuscripts at

http://www.hindawi.com
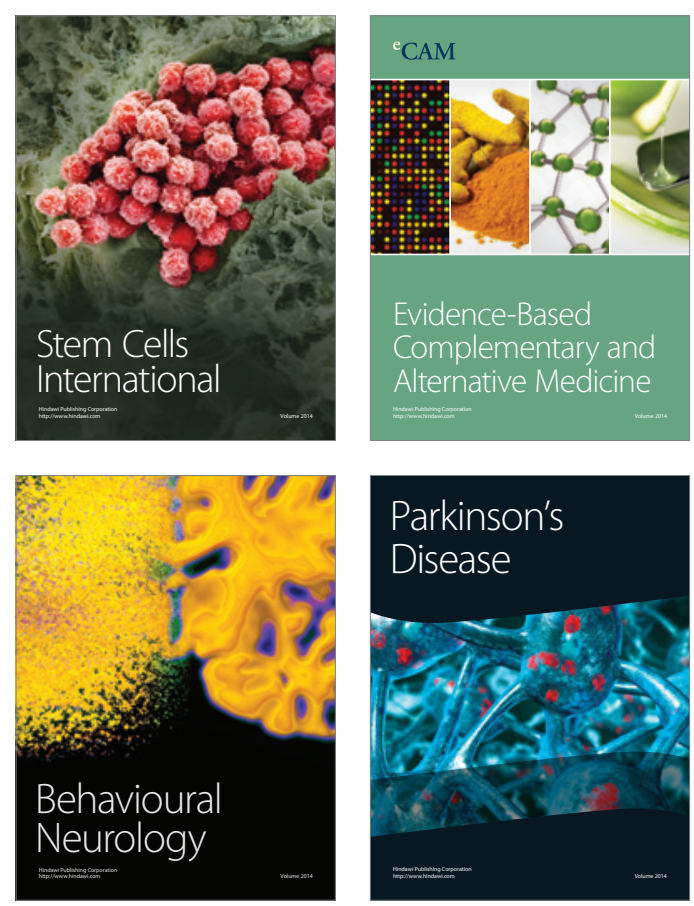

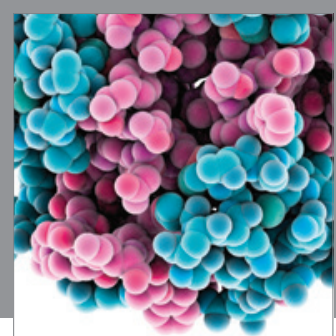

Journal of
Diabetes Research

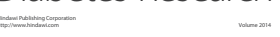

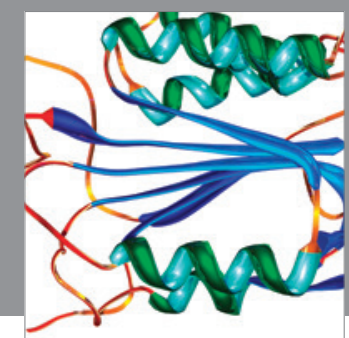

Disease Markers
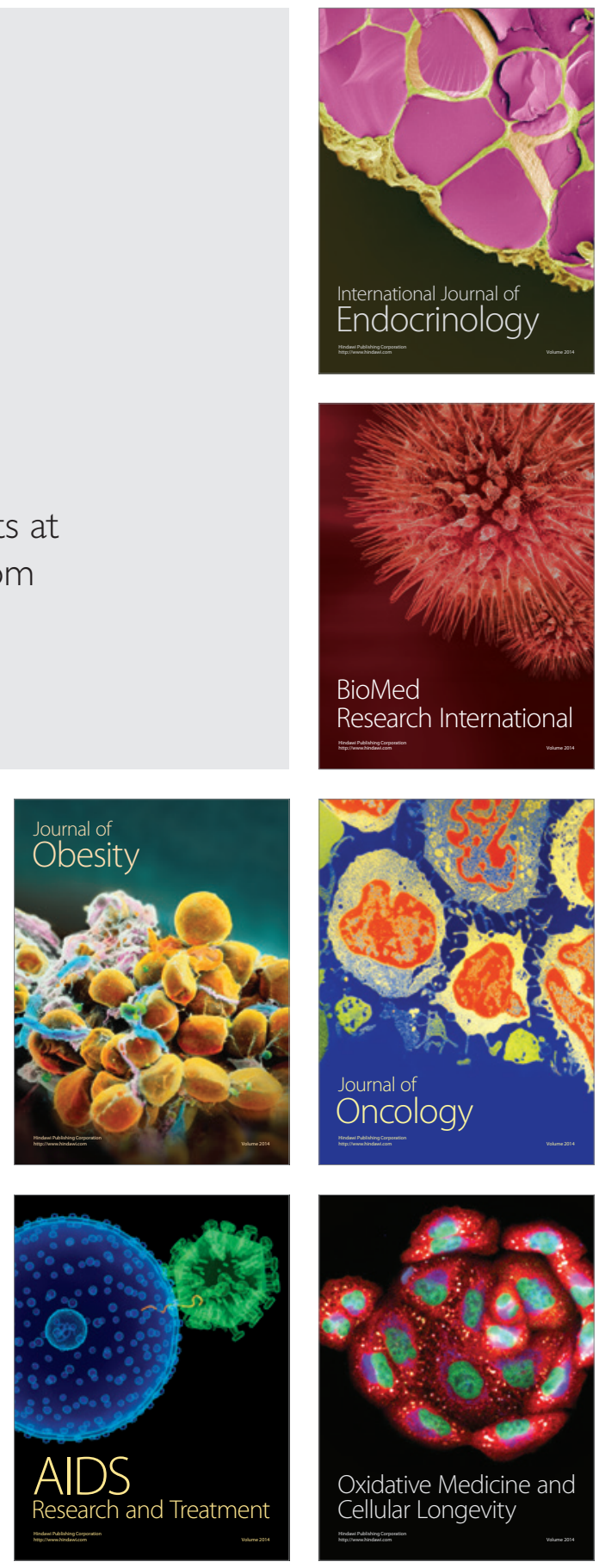